\title{
Frequency and Severity of Imposter Syndrome among Medical Students of a Private Medical College
}

Ambreen Khalid ${ }^{1}$, Adeela Shahid ${ }^{2}$, Khalid Rahim Khan ${ }^{3}$

Department of Physiology, Shalamar Medical \& Dental College, Lahore ${ }^{1,2}$

Radiology Department, Cantonment General Hospital, Lahore ${ }^{3}$

\begin{abstract}
Background: Students suffering from imposter syndrome/phenomenon (IP) consider themselves less competent and less skill full as compared to the abilities they actually possess. Although previous research has identified different causes of stress and burnout but less research has been conducted to determine the frequency of imposter syndrome among medical undergraduate students.
\end{abstract}

Objectives: (1) To determine the frequency and the degree of severity of Imposter syndrome among medical students. (2) To find out the association of Gender with imposter syndrome. (3) To evaluate the difference in the severity of imposter syndrome between $1^{\text {st }}$ and $2^{\text {nd }}$ year MBBS students.

Methods: The cross sectional study was conducted on $1401^{\text {st }}$ and $2^{\text {nd }}$ year MBBS students of Shalamar Medical and Dental College, Lahore. Convenient sampling technique was used. The study instrument used was a validated questionnaire (Clance IP Scale) containing 20 items with 5 point Likert scale. By adding up the score, the degree of severity is determined. Frequencies \& percentages were determined, chi-square applied, $p$-value $<0.05$ was considered significant.

Results: One hundred and 40 students filled the IP Scale questionnaire. The frequency of imposter syndrome was $53.3 \%$ among medical students. Majority $(85 \%)$ of the medical students had frequent to intense imposter characteristics. Higher number of female students was affected by imposter phenomenon as compared to males. Greater number of $1^{\text {st }}$ year students were suffering from imposter syndrome as compared to $2^{\text {nd }}$ year students.

Conclusions: Frequency of imposter syndrome was high among medical students. Its severity ranges from moderate to frequent IP categories in majority of students. Female students were affected more as compared to their male counterparts.

Key Words: Imposter Syndrome, Medical students, Imposter Phenomenon

\section{INTRODUCTION}

\section{Corresponding Author:}

Dr. Ambreen Khalid

Associate Professor

Department of Physiology

Shalamar Medical and Dental College Lahore

Email address: ambreenkr@yahoo.com

Received 18.07.19, Revised 20.07.19, Accepted 24.07. 19
Imposter Syndrome also called Imposter phenomenon (IP) is a condition in which the sufferer has feelings of self-doubt and fear of being exposed as an intellectual fraud despite the evidence of capabilities. ${ }^{1}$ They give the credit of their successes to the stroke of luck or a coincidental instead of their abilities. These 
feelings were particularly powerful at the beginning of new careers, jobs, or projects. ${ }^{2}$ The psychological researchers Pauline Clance and Suzanne Imes were the first one to discover it among high achiever females in $1978 .^{3}$ Initially it was found in successful women but later Clance identified this syndrome in both gender and among other highly accomplished people. ${ }^{4}$ Interestingly, research shows that IP is still at its highest amongst academics, at a rate of $70 \%$, but this is not a syndrome confined to working professionals. The frequency of imposter syndrome was found to be $30 \%$ in medical, dental, pharmacy, and nursing students, while $45-57 \%$ in some other countries. ${ }^{5}$ Its frequency was $43.8 \%$ in internal medicine residents $^{6}$ moreover, the literature strongly suggests a higher levels of IP in females. ${ }^{6}$ IP has several possible repercussions for medical education ${ }^{7}$ because medical students are among the high risk groups for imposter syndrome as it is more prevalent in high achievers. ${ }^{8}$ Those suffering from IP are hesitant to speak up or volunteer for answers and information as compared to their unaffected peers. ${ }^{5}$ IP was considered to be the strongest predictor of wideranging psychological distress. ${ }^{9}$ Students with IP had significantly increased levels of burnout, emotional exhaustion, depersonalization and cynicism. ${ }^{5}$ Perfectionism has been linked to imposter syndrome due to a predisposition to focus on one's shortcomings. ${ }^{10}$ Hence, the understanding of imposter phenomenon will help us to detect the medical students who are at risk of leaving the studies or medical profession later because they feel themselves incapable to fulfill the institutional and professional expectation. ${ }^{3}$ Though the impostor phenomenon has been identified in teachers, students and business experts, it has not been studied well in undergraduate medical students. ${ }^{6}$ The present study was designed to determine the frequency and the degree of severity of Imposter syndrome among medical students and to find out any difference with respect to gender. The difference in the severity of imposter syndrome between $1^{\text {st }}$ and $2^{\text {nd }}$ year MBBS students was also evaluated.

\section{MATERIALS AND METHODS}

A cross-sectional, study was conducted from April to August, 2018 at Shalamar medical \& dental College, Lahore after taking informed consent from the students and approval from Institutional Review Board (IRB). Convenient sampling technique was used, 140 students of Shalamar medical and dental college participated in the study. A complete history was taken from the subjects in relation to any systemic or psychiatric illness like anxiety, depression and schizophrenia as these affect the degree of severity and pattern of imposter syndrome. Students with known chronic medical illnesses or those who were taking drugs or sessions from psychologist due to any psychiatric illness were excluded from the study. The study instrument used was a validated questionnaire, Clance Imposter Phenomenon Scale (CIPS). It is a 20-item questioner with each consisting of 5 parameters showing severity from none to very severe levels. ${ }^{1,5}$ The twenty component scores are then added to yield a global CIPS score in the range of 20 to 100 ; the higher the score is, the worse the imposter syndrome. Any participant scoring 62 was considered an 'imposter". All symptoms of imposter syndrome were evaluated on basis of these parameters. Questions regarding age, gender and year of study were added in the questionnaire. The questionnaire was generated in Google forms and the link was shared with the participants.

\section{Statistical Analysis}

SPSS version 21 was used for statistical analysis. Frequencies and percentages were calculated, Chi square test was applied to determine association of gender and academic year of MBBS with IP.

\section{RESULTS}

The questionnaire was sent to 200 students, 140 students returned the questionnaire (Clance IP Scale) hence the response rate was $70 \%$. Out of 
140 students $89(64 \%)$ were females and 51(36\%) were males (Fig 1), 84(60\%) belonged to $1^{\text {st }}$ year and $56(40 \%)$ belonged to second year (Fig 2). The overall mean age of the respondents was $20.03 \pm 1.051$ years whereas mean age of male and female students was $20.05 \pm 1.12$ and $19.51 \pm 1.006$ years respectively.

Figure 1: Percentage of Male and Female Students

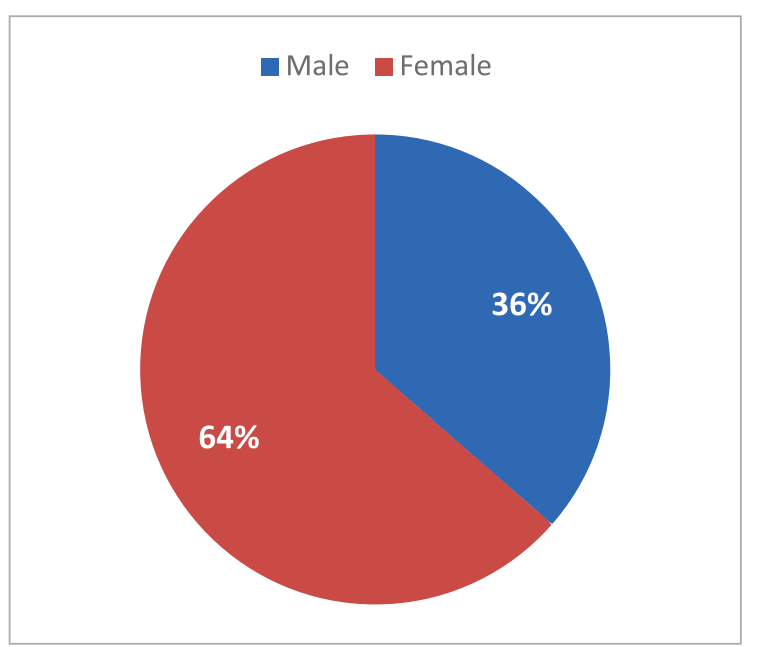

Figure 2: Percentage of 1st and 2nd Year MBBS Students

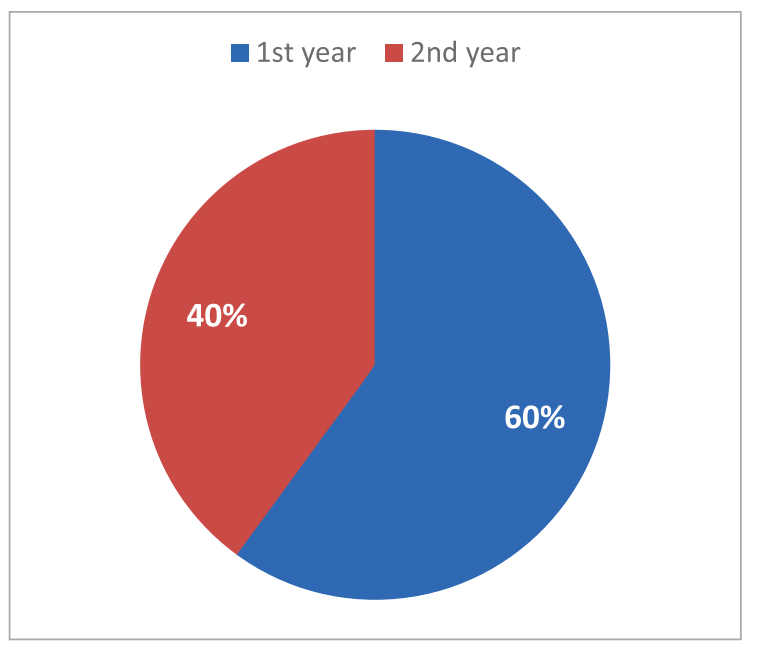

Table 1: Clance IP Scoring Chart Used to Determine the Severity of Imposter Syndrome

\begin{tabular}{|l|c|l|}
\hline \multicolumn{3}{|c|}{ Clance IP Scoring Chart } \\
\hline S. No & Score & Degree of Severity \\
\hline 1 & $<40$ & Few IP Characteristics \\
\hline 2 & $40-60$ & Moderate IP Experience \\
\hline 3 & $61-80$ & Frequent IP Experience \\
\hline 4 & $>80$ & Intense IP Experience \\
\hline
\end{tabular}

Table 2: Imposter Phenomenon (IP) Characteristics of Whole Study Population

\begin{tabular}{|l|l|c|}
\hline \multicolumn{1}{|c|}{ Scores } & \multicolumn{1}{|c|}{ Scale } & n (\%) \\
\hline$<40$ & Few IP characteristics & $6(4.3)$ \\
\hline $41-60$ & Moderate IP Experiences & $60(43.1)$ \\
\hline $61-80$ & Frequent Imposter Feelings & $60(43.1)$ \\
\hline$>80$ & Intense IP Experiences & $14(10.2)$ \\
\hline
\end{tabular}

The frequency of imposter syndrome was 53.3\% among medical students. The IP characteristics of all respondents are shown in Table 2. Few IP characteristics were experienced by 6 students $(4.3 \%)$, moderate IP characteristics were experienced by 60 students $(43.1 \%)$, and frequent IP characteristics were experienced by 60 students (43.1\%) while Intense IP characteristics were experienced by $14(10.2 \%)$ students (Table 2).

Table 3: Severity of IP Characteristics among Male and Female

\begin{tabular}{|l|l|l|}
\hline IP Characteristics & $\begin{array}{l}\text { Males } \\
\mathbf{n}(\text { Expected cell } \\
\text { frequency } / \boldsymbol{\alpha} \mathbf{2})\end{array}$ & $\begin{array}{l}\text { Females } \\
\mathbf{n}(\text { Expected cell } \\
\text { frequency } / \boldsymbol{\chi} \mathbf{2})\end{array}$ \\
\hline Few IP & $3(2.19 / 0.30)$ & $3(3.81 / 0.17)$ \\
\hline Moderate IP & $26(21.86 / 0.79)$ & $34(38.14 / 0.45)$ \\
\hline frequent IP & $18(21.86 / 0.68)$ & $42(38.14 / 0.39)$ \\
\hline Intense IP & $4(5.10 / 0.24)$ & $10(8.90 / 0.14)$ \\
\hline
\end{tabular}

The chi-square value was 3.15 and $p$ value was 0.3681 . The IP characteristics of male and female students after scoring of all questions according to Clance IP Scale are shown in the figure 3 and Table 3. Among 6 participants having few IP characteristics, number of male and female students were equal $(50 \%)$. Out of 60 participants that experienced moderate IP characteristics there were 26(43.3\%) males and $34(56.6 \%)$ females. More female students $(n=42)$ compared to males $(n=18)$ among 60 participants suffered from frequent imposter feeling. Among 14 participants who had Intense IP Experience there were 10 female and only 4 male students. Female medical students were observed to have more IP characteristics, but it was statistically not significant, chi-square statistics was 3.15 and $p$ value was 0.3681 (Figure 3, Table 3). 
Figure 3: Comparison of IP Characteristics among Male and Female MBBS Students

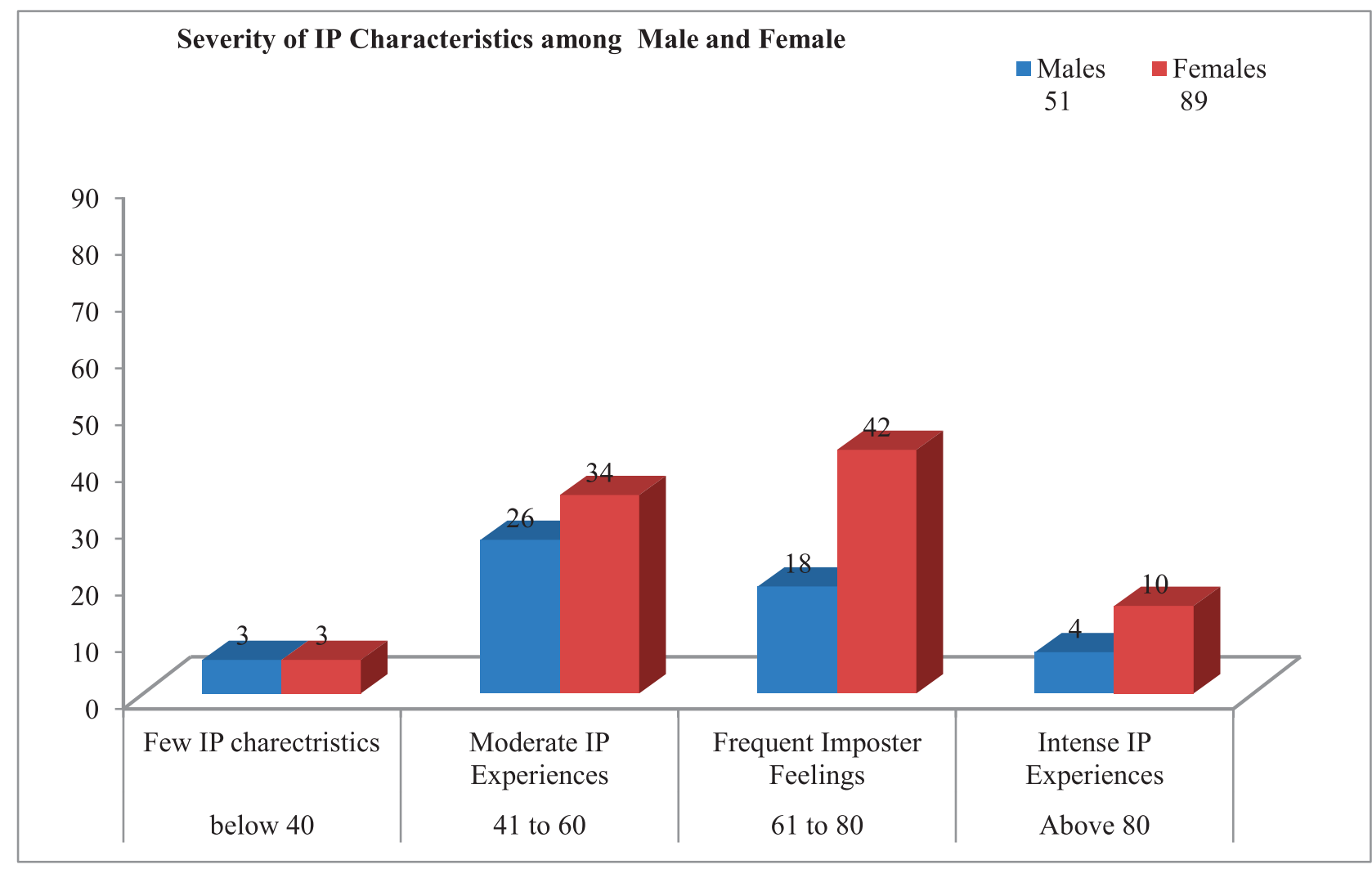

Table 4: Severity of IP Characteristics among 1st and 2nd Year MBBS Students

\begin{tabular}{|l|c|c|}
\hline \multicolumn{1}{|c|}{ IP Characteristics } & $\begin{array}{c}\mathbf{1}^{\text {st }} \text { year } \\
\text { (Expected cell } \\
\text { frequency } / \boldsymbol{\chi} \mathbf{2})\end{array}$ & $\begin{array}{c}\mathbf{2}^{\text {nd }} \text { year } \\
\text { (Expected cell } \\
\text { frequency } / \boldsymbol{\chi} \mathbf{2})\end{array}$ \\
\hline Few IP & $1(3.60 / 1.88)$ & $5(2.49 / 2.82)$ \\
\hline Moderate IP & $39(36 / 0.25)$ & $21(24 / 0.38)$ \\
\hline Frequent IP & $35(36 / 0.03)$ & $25(24 / 0.04)$ \\
\hline Intense IP & $9(8.40 / 0.04)$ & $5(5.60 / 0.06)$ \\
\hline
\end{tabular}

Chi-square value was 5.496 and p value was 0.138. Table 4 shows the IP characteristics among $1^{\text {st }}$ year and $2^{\text {nd }}$ year MBBS students, among 84 participants $39(46.4 \%)$ experienced moderate, $35(41.6 \%)$ experienced frequent while only $9(10.7 \%)$ experienced intense and $1(1.1 \%)$ showed few IP characteristics. Among 56 second year medical students, 21(37.5\%) showed moderate imposter feelings, 25(44.6\%) exhibit frequent imposter feelings while only $5(8.9 \%)$ students showed few and intense IP characteristics. $1^{\text {st }}$ year MBBS students appeared to have more IP characteristics however, this difference was statistically not significant, chi- square statistics was 5.496 and $\mathrm{p}$ value was 0.138 (Table 4).

\section{DISCUSSION}

Imposter syndrome was found to be the strongest predictor of general psychological distress. Strong association of imposter syndrome with multiple components of burnout, anxiety, depression and self-esteem issues has been reported in the literature. ${ }^{11}$ The frequency of imposter syndrome is $53.3 \%$ among medical Students in the current study. A research conducted on medical, dental, nursing, and pharmacy students revealed 30\% impostors among the participants of their study. ${ }^{5}$ Oriel et al, found $45.9 \%$ prevalence of family medicine residents. ${ }^{7}$ Similar trend is shown by another study conducted on Malaysian medical students that also reported $45.7 \%$ frequency of imposter syndrome. ${ }^{12}$ Current study not only determined the frequency of imposter syndrome but also found the degree of severity of this syndrome among medical students. Few IP characteristics 
were experienced by 6 students (4.3\%), moderate IP characteristics by 59 students (42.4\%), and frequent IP characteristics by 60 students (43.1\%), while Intense IP characteristics were experienced by $14(10.2 \%)$ students. Comparable to this study also assessed and categorized the medical students of Nishtar medical university according to the degree of severity, by using Clance IP scale and reported slightly variable results. According to that study Few IP characteristic was present in $2.64 \%$, moderate IP in $38.09 \%$, Frequent IP in $54.49 \%$ and very intense IP in $4.76 \%{ }^{3}$ Current studies showed that the number of females suffering from IP was greater in all categories except for the mild form of IP in which the number of male and female was equal. Maqsood et al, also reported female preponderance in the category of moderate, frequent and intense IP experience while male dominance in mild and few IP experience characteristics. ${ }^{3}$ Though earlier studies have shown mix trends regarding the gender distribution yet initially imposter phenomenon was found to be predominant in high achieving women. ${ }^{2}$ However, further studies showed that this phenomenon is also quite frequent among males. ${ }^{12}$ Some researchers found the gender variable to be insignificant regarding the prevalence as well as the severity of imposter phenomenon. However, most of the studies showed females as relatively common sufferers like the current study so, results of present study coincides with the previous studies showing that females are comparatively more affected by IP. In most of the medical colleges in Pakistan, there are more female students as compared to male students. So, the high prevalence of imposter phenomenon affects significantly on the majority of individuals during medical education and training. ${ }^{3}$ Greater percentage of $1^{\text {st }}$ year students had moderate and intense IP experience as compared to $2^{\text {nd }}$ year students while, few and frequent IP experience was found more in $2^{\text {nd }}$ year MBBS students. However the difference was not significant. Similar results were reported by Jostl et al, that promotion into senior classes does not affect the
IP phenomenon. ${ }^{13}$ Maqsood et al, also reported no association between the year of study and severity of imposter syndrome which is also in accordance with our study. ${ }^{3}$

\section{CONCLUSION}

The frequency of imposter syndrome is high among medical students. Its severity ranges from moderate to frequent imposter characteristics in majority of students. Female students are affected more as compared to their male counterparts.

\section{Recommendations}

Imposter syndrome may reduce the productivity of a medical professional. Thus, identification of the students should be done who are at risk of leaving the institution or profession due to misconception of being incompetent to handle the institutional and professional responsibilities. The institutions should implement extensive programs for helping the students suffering from imposter phenomenon. Students can be trained to boast their self-esteem, understand perfectionism and for setting goals that are reasonable and achievable.

\section{Acknowledgements}

Authors are grateful to all MBBS students of $1^{\text {st }}$ and $2^{\text {nd }}$ year who participated in the study.

\section{Conflicts of interest}

The authors had no conflicts of interest to disclose.

\section{Contributors}

Manuscript writing and data collection was done by Dr. Ambreen Khalid, Statistical analysis and proof reading done by Dr. Adeela Shahid, Idea of the research, IP scoring and compilation of results was done by Lt. Col Dr. Khalid Rahim Khan.

\section{REFERENCES}

1. Parkman A. The imposter phenomenon in higher education: Incidence and impact. Journal of Higher Education Theory and Practice, JHETP. 2016; 16(1): $51-60$. 
2. Clance PR, Imes SA. The imposter phenomenon in high achieving women: Dynamics and therapeutic intervention. Psychotherapy: Theory Research \& Practice. 1978; 15(3): 241-7.

3. Maqsood H, Shakeel HA, Hussain H, Khan AR, Ali B, Ishaq A, et al, The descriptive study of imposter syndrome in medical students. Int $\mathrm{J}$ Res Med Sci. 2018; 6(10): 3431-4.

4. Legassie J, Zibrowski EM, Goldszmidt MA. Measuring resident well-being: impostorism and burnout syndrome in residency. $\mathrm{J}$ Gen Intern Med. 2008; 23(7):1090-4.

5. Villwock JA, Sobin LB, Koester LA, Harris TM. Impostor syndrome and burnout among American medical students: a pilot study. Int J Med Educ. 2016; 7: 364-9.

6. Sherman RO. Imposter syndrome: When you feel like you're faking it. Am Nurse Today. 2013; 8(5): 57-8.

7. Oriel K, Plane MB, Mundt M. Family medicine residents and the impostor phenomenon. Fam Med. 2004; 36(4):248-52.

8. Qureshi MA, Taj J, Latif MZ, Zia S, Rafique M, Chaudhry MA. Imposter syndrome among Pakistani medical students. Annals of KEMU. 2017; 23(2): 106-10.

9. Sakulku J, Alexander J. The Impostor Phenomenon. International Journal of Behavioral Sciences. 2011; 6(1): 73-92.

10. Wang KT, Sheveleva MS, Permyakova TM. Imposter syndrome among Russian students: The link between perfectionism and psychological distress. Personality and Individual Differences. 2019; 143:1-6.
11. Ghorbanshirodi S. The relationship between self-esteem and emotional intelligence with impostor syndrome among medical students of Guilan and Heratsi universities. Journal of Basic and Applied Scientific Research. 2012; 2(2): 1793-02.

12. Bonilla-Velez J, Peña-Oscuvilca A, Sahin I, Cordoba-Grueso WS, Fernandez-Zapico ME. The international journal of medical students, a platform for medical student research worldwide. International Journal of Medical Students. 2013;1(1):6-7.

13. Jöstl G, Bergsmann E, Lüftenegger M, Schober B, Spiel C. When will they blow my cover? Zeitschrift für Psychologie. 2012 ; 220(2):109120.

14. Wang KT, Sheveleva MS, Permyakova TM. Imposter syndrome among Russian students: The link between perfectionism and psychological distress. Personality and Individual Differences. 2019; 143:1-6.

15. Ghorbanshirodi S. The relationship between self-esteem and emotional intelligence with impostor syndrome among medical students of Guilan and Heratsi universities. Journal of Basic and Applied Scientific Research. 2012; 2(2): 1793-02.

16. Bonilla-Velez J, Peña-Oscuvilca A, Sahin I, Cordoba-Grueso WS, Fernandez-Zapico ME. The international journal of medical students, a platform for medical student research worldwide. International Journal of Medical Students. 2013;1(1):6-7.

17. Jöstl G, Bergsmann E, Lüftenegger M, Schober $\mathrm{B}$, Spiel C. When will they blow my cover? Zeitschrift für Psychologie. 2012; 220(2):109120. 